\title{
Oxygen Isotope Equilibrium between Muscovite and Water ${ }^{1}$
}

\author{
JAMES R. O'NeIL \\ U. S. Geological Survey, Menlo Park, California 94025 \\ Hugh P. Taylor, JR. \\ Division of Geological Sciences \\ California Institute of Technology, Pasadena, California 91109
}

\begin{abstract}
Oxygen isotopes have been equilibrated between muscovite and aqueous alkali chloride solution and between paragonite and alkali chloride solution in the temperature range of $400^{\circ}-650^{\circ} \mathrm{C}$ at 1 and $1.5 \mathrm{~kb}$ fluid pressure. Isotopic equilibrium was inferred from the fact that compatible fractionation factors were obtained using 3 different chemical reactions to produce the mica: (1) muscovite or paragonite was prepared by reacting natural kaolinite with 2-3 molal $\mathrm{KCl}$ or $\mathrm{NaCl}$ solutions; (2) muscovite was crystallized in pure water from a gel; and (3) synthetic paragonite was reacted with 2-3 molal $\mathrm{KCl}$ solution, producing muscovite by an alkali ion exchange reaction. The $1 M$ modification of the mica was made in every experiment. In several cases the extent of oxygen exchange was traced by running companion equilibrations in solutions of unusually low $\mathrm{O}^{18} / \mathrm{O}^{10}$ ratio. No isotopic fractionation was discernible between muscovite and paragonite in the temperature range studied. Per mille fractionations between muscovite and water are given by the expression $10^{3} \ln \alpha=2.38\left(10^{8} T^{-2}\right)$ -3.89 . These data can be combined with the results of other laboratory equilibration studies to establish a set of calibrated oxygen isotope geothermometers. Analogous to the alkali feldspar systems previously reported, the direct relationship between cation and oxygen isotope exchange suggests that some type of solution-redeposition mechanism operated during muscovite-paragonite transformations in aqueous solutions. Also, the extensive oxygen isotope exchange (with the solution) that accompanies the formation of muscovite from kaolinite implies a breakdown of the kaolinite structure. This notion does not concur with hypotheses based on rate studies and X-ray measurements that the unaltered kaolinite structure is partially inherited by the mica.
\end{abstract}

\section{INTRODUCTION}

Muscovite is the most common mica occurring in nature. It is formed under a wide variety of geologic conditions and is abundant in finegrained sediments and many metamorphic rocks, as well as in some aluminous igneous rocks. Extensive laboratory investigations have elucidated the nature of its various stacking polymorphs and their stability fields [Yoder and Eugster, 1955; Velde, 1965, 1966]. Oxygen isotope analyses of muscovites were first reported by Taylor and Epstein [1962a] and Taylor et al. [1963], who showed that, in general, muscovite occupies a specific position in

${ }^{1}$ Publication authorized by the Director, U. S. Geological Survey, Publications of the Division of Geological Sciences, California Institute of Technology, Contribution No. 1479.

Copyright (C) 1969 by the American Geophysical Union. the sequence of common rock-forming minerals with respect to the tendency to concentrate $O^{18}$. A set of coexisting minerals commonly exhibits decreasing $0^{18} / 0^{16}$ ratios in the sequence: quartz, alkali feldspar, sodic plagioclase, calcic plagioclase, muscovite, hornblende, biotite, and magnetite. Other analyses of muscovite have been reported by Garlick and Epstein [1967], Taylor [1967, 1968], Taylor and Coleman [1968], and Shieh and Taylor [1969]. These authors indicate that oxygen isotope fractionations between quartz and muscovite in metamorphosed rocks generally decrease with an increasing grade of metamorphism as judged on petrological and geological grounds. Measured fractionations range from about $2.0 \%$ in igneous rocks and high-grade metamorphic rocks to $5.0 \%$ in low-grade rocks.

The laboratory study of the equilibrium oxygen isotope properties of muscovite reported 
In this paper is a direct outgrowth of a similar study on the feldspars [O'Neil and Taylor, 1967]. In addition to obtaining information on the nature of the mineralogical reactions involving micas, these studies (in conjunction with those of Clayton, O'Neil, and Mayeda on the quartz-water system) establish a calibrated quartz-muscovite oxygen isotope thermometer. This pair will probably prove to be one of the most useful among coexisting silicates because of the ubiquity of the minerals and the moderately high temperature sensitivity of the isotopic fractionations.

\section{Experimental Procedures}

All hydrothermal experiments were carried out in sealed gold capsules using coldseal bombs. Temperatures were monitored with ChromelAlumel thermocouples and were constant throughout the run to $\pm 3^{\circ} \mathrm{C}$. The fluid pressures were maintained at 1000 or 1500 bars. The bombs were quenched to room temperature in a few minutes by a combination of cold air blasts and immersion in cold water. When large coldseal bombs were used, the quench times were of the order of 5-10 min, but the differences in quench times had no discernible effects. After quench, the solids were removed from the gold capsules, washed in water and acetone, and dried in an oven. The oxygen was liberated from the solids by reaction with fluorine gas at $500^{\circ} \mathrm{C}$ [Baertschi and Silverman, 1951; Taylor and Epstein, 1962a] and then converted to carbon dioxide for analysis on the mass spectrometer. This analytical procedure has an error of $\pm 0.1-0.2 \%$ for a single analysis. The starting solutions were analyzed directly for $\mathrm{O}^{10}$ content by the $\mathrm{BrF}_{5}$ method of O'Neil and Epstein [1966]. The post-reaction solutions were not analyzed, but because this oxygen constituted about $93 \%$ of the oxygen in the system, their isotopic compositions were calculated with sufficient accuracy by material balance.

The oxygen isotope exchange rates of natural micas were found to be prohibitively slow in pure water, and other methods (simple recrystallization in waters of different isotopic composition) had to be developed. The following procedures were ultimately used in obtaining the oxygen isotope fractionation factors between muscovite (and paragonite) and water.
1. Formation of $1 M$ maca from natural kaolinite.

$$
\begin{aligned}
& 0.75 \mathrm{Al}_{4}(\mathrm{OH})_{8} \mathrm{Si}_{4} \mathrm{O}_{10} \\
& \text { kaolinite } \\
& \qquad \mathrm{Na}^{+} \rightarrow \\
& \mathrm{NaAl}_{2}(\mathrm{OH})_{2} \mathrm{AlSi}_{3} \mathrm{O}_{10}+\mathrm{H}^{+}+1.5 \mathrm{H}_{2} \mathrm{O} \\
& \text { paragonite }
\end{aligned}
$$

Natural kaolinite from the McNamee mine in Georgia, with a potassium content of less than $0.1 \%$ was used in this procedure. The solutions were 2-3 molal alkali chloride. No reaction occurred after 1176 hours at $290^{\circ} \mathrm{C}$. However, at higher temperatures, reaction times were extremely rapid. In one case, complete transformation (determined by X-ray diffraction) was observed after only 15 minutes at $500^{\circ} \mathrm{C}$. The nature of this reaction will be discussed in a later section. Paragonite or muscovite (the $1 M$ modification in all cases) was produced with equal facility by using either sodium chloride or potassium chloride solutions. Most of the runs were made with starting materials that were already very near isotopic equilibrium. The $\delta$-values of the kaolinite, Water-7, and Water-2 are $+4.0,+4.9$, and +1.2 , respectively. These materials offer the advantage of being close in isotopic composition to the working standard of the mass spectrometer. Four runs were made in Water-4, which is about $40 \%$ lighter in $0^{18} / \mathrm{O}^{18}$ ratio than Water-7, and five runs were made in a water of intermediate composition (Water-3). Gross oxygen isotope redistribution accompanied all these transformations, and at a given temperature the resultant mica-water fractionations were the same in all three solutions. The observed isotopic fractionations could be a consequence of (a) equilibrium isotope distribution, (b) kinetic isotope fractionation effects associated with the chemical reaction, or (c) incomplete exchange.

2. Crystallization of muscovite gel. A gel of muscovite composition was crystallized in pure water. The temperature range over which this procedure can be used is very small and only one experiment was made (at $600^{\circ} \mathrm{C}$ ).

3. Alkali ion (and $O^{\text {19 }}$ ) exchange reaction. $\underset{\text { paragonite }}{\mathrm{NaAl}_{2}(\mathrm{OH})_{2} \mathrm{AlSi}_{2} \mathrm{O}_{10}+\mathrm{K}^{+} \rightarrow}$

$\mathrm{KAl}_{2}(\mathrm{OH})_{2} \mathrm{AlSi}_{3} \mathrm{O}_{10}+\mathrm{Na}^{+}$ muscovite 
TABLE 1. Oxygen Isotope Fractionation Data for Procedures 1 and 2

\begin{tabular}{|c|c|c|c|c|c|}
\hline Sample No. & Description* & Temp., ${ }^{\circ} \mathrm{C}$ & Time, hours & Water $t$ & $10^{3} \ln \alpha$ \\
\hline \multicolumn{6}{|c|}{ Procedure 1} \\
\hline 366 & Kaol. $+2 M \mathrm{NaCl}$ & 650 & 2 & 7 & -1.26 \\
\hline 56 & Kaol. + $2 M \mathrm{KCl}$ & 630 & 15 & 3 & -0.94 \\
\hline 355 & Kaol. $+3 M \mathrm{NaCl}$ & 610 & 13 & 7 & $-0.30 \ddagger$ \\
\hline 349 & Kaol. $+2 M \mathrm{KCl}$ & 600 & 90 & 7 & -0.81 \\
\hline 351 & Kaol. $+2 M \mathrm{NaCl}$ & 600 & 90 & 7 & -0.82 \\
\hline 358 & Kaol. $+2 M \mathrm{KCl}$ & 600 & 21 & 4 & $-0.35 \ddagger$ \\
\hline 317 & Kaol. $+2 M \mathrm{KCl}$ & 550 & 25 & 2 & -0.30 \\
\hline 58 & Kaol. $+3 M \mathrm{NaCl}$ & 510 & 71 & 3 & $-0.60 \ddagger$ \\
\hline $61 A$ & Kaol. $+3 M \mathrm{NaCl}$ (grain exteriors) & 510 & 180 & 4 & +0.05 \\
\hline $61 B$ & Kaol. $+3 M \mathrm{NaCl}$ (grain interiors) & 510 & 180 & 4 & $(+2.04) \ddagger$ \\
\hline 73 & Kaol. $+2 M \mathrm{KCl}$ & 510 & 0.3 & 3 & -0.02 \\
\hline 346 & Kaol. $+2 M \mathrm{KCl}$ & 500 & 360 & 7 & -0.21 \\
\hline 352 & Kaol. $+2 M \mathrm{NaCl}$ & 500 & 304 & 7 & $-0.53 \ddagger$ \\
\hline 354 & Kaol. + $2 M \mathrm{KCl}$ & 500 & 120 & 7 & +0.05 \\
\hline 139 & Kaol. $+3 M \mathrm{NaCl}$ & 420 & 635 & 3 & +0.95 \\
\hline 142 & Kaol. $+3 M \mathrm{KCl}$ & 420 & 635 & 3 & +1.07 \\
\hline 341 & Kaol. $+2 M \mathrm{KCl}$ & 400 & 1176 & 4 & +1.36 \\
\hline 342 & Kaol. $+2 M \mathrm{KCl}$ & 400 & 1176 & 7 & +1.21 \\
\hline 347 & Kaol. $+2 M \mathrm{KCl}$ & 400 & 523 & 4 & +1.51 \\
\hline \multicolumn{6}{|c|}{ Procedure 2} \\
\hline 106 & Musc. gel $+\mathrm{H}_{2} \mathrm{O}$ & 600 & 114 & 7 & -0.78 \\
\hline
\end{tabular}

* Kaol. = kaolinite. Musc. $=$ muscovite.

$\dagger \delta_{\text {Water-2 }}=+1.16, \delta_{\text {Water-3 }}=-11.73, \delta_{\text {Water-4 }}=-35.96, \delta_{\text {Water-7 }}=+4.93$.

$\mathfrak{f}$ Not used in calculating the least-squares expression (see text). Parentheses indicate demonstrably nonequilibrium value.

Reactant materials were micas made from kaolinite, as in procedure (1), and 2-3 molal alkali chloride solutions. These exchange reactions are directly analogous to those observed in alkali feldspar systems [O'Neil and Taylor, 1967]. Alkali contents of muscovite from one run were determined by emission spectrographic analysis. The results ( $\mathrm{K}>5 \% ; \mathrm{Na}<1 \%$ ) indicated extensive but incomplete alkali exchange in 67 hours at $500^{\circ} \mathrm{C}$. It is interesting to note that these mica-exchange reartions occur at a markedly slower rate than the kaolinite reactions of procedure (1), and they also occur more slowly than the analogous exchange reactions in alkali feldspars. Most of the mica exchange runs also were made with materials that were already very near isotopic equilibrium. In these runs, the starting mica was prepared in Water-2 (or in one case with Water-7) and then exchanged with the appropriate alkali chloride solution also made with Water-2 (or Water-7). Five companion runs were made in Water-4, which is approximately 35\% lighter in $0^{18} / 0^{19}$ ratio than Water-2. Even though these runs indicate that isotopic exchange was only 65 to $85 \%$ complete, the runs made in Water-2 (and Water-7) started sufficiently close to the equilibrium values that the data points can be used to provide equilibrium information (see below).

\section{Experimental Results}

The oxygen isotope fractionations and descriptions of the experiments in which they were measured are given in Tables 1 and 2. The 350$650^{\circ} \mathrm{C}$ temperature range of these experiments is fixed by muscovite breakdown at high temperatures and slow exchange rates at low temperatures. For the kaolinite reactions, apparent equilibrium values were obtained using four different waters (not at each temperature, however), and thus the equilibrium distribution of isotopes was approached from: (a) both sides of the equilibrium curve, and (b) a variety of 'distances' away from equilibrium. The fractionations are given in terms of $1000 \ln \alpha$ where 


$$
\alpha=\frac{\left(\mathrm{O}^{18} / \mathrm{O}^{10}\right) \text { muscovite }}{\left(\mathrm{O}^{18} / \mathrm{O}^{18}\right) \text { water }}
$$

$\alpha$ is essentially the equilibrium constant for the isotope exchange reaction between muscovite and water (written so that a single atom is exchanged):

$$
\begin{aligned}
& \frac{1}{12} \mathrm{KAl}_{2}\left(\mathrm{AlSi}_{3} \mathrm{O}_{10^{16}}\right)\left(\mathrm{O}^{16} \mathrm{H}\right)_{2}+\mathrm{H}_{2} \mathrm{O}^{18} \rightarrow \\
& \frac{1}{12} \mathrm{KAl}_{2}\left(\mathrm{AlSi}_{3} \mathrm{O}_{10}{ }^{18}\right)\left(\mathrm{O}^{18} \mathrm{H}\right)_{2}+\mathrm{H}_{2} \mathrm{O}^{16}
\end{aligned}
$$

Excluding the stripping experiment datum $(61 B)$, which is discussed below, Table 1 shows 18 fractionations for procedure (1) measured at various temperatures. Fourteen of these fractionations are possible equilibrium values, and when they are plotted as $\ln \alpha$ versus $T^{-2}$ in Figure 1, the data points lie on a straight line given by the expression: $10^{3} \ln \alpha=2.43\left(10^{6} T^{-2}\right)-4.02$. A straight line relationship is justified by theoretical arguments of Urey [1947] and Bigeleisen and Mayer [1947] and by previous experimental work. The four points in Figure 1 that do not lie on the least-squares line represent runs that appeared normal in every respect other than the final isotopic composition of the mica. These points deviate only about $0.5 \%$ o from the leastsquares line; this amount is considerably outside the presumed analytical error, however, and the points are therefore rejected. Similar anomalies have been observed in previous laboratory calibrations of oxygen isotope geothermometers; considering the number of steps in the procedures and the precision entailed, these anomalies are to be expected.

The arrows shown in Figure 1 indicate the direction in which the value of $10^{3} \ln \alpha$ changed during each run. The runs made in the low $O^{18}$ waters ( 3 and 4 ) have arrows pointing downward since the silicate material becomes progressively lighter. The opposite is true for runs made in the heavier Water-7. Runs in Water-2 are so close to equilibrium at the start that the direction of the arrow depends on the temperature of the run. Only one run was made in Water-2, and for this case the arrow points downward. Note that the silicate material changed by almost $40 \%$ in the four runs made in Water-4. Depending on the exact mechanism of the kaolinite-mica reaction, the two-direction approach outlined here may or may not be a valid test of equilibrium.

Data points from procedures (2) and (3) are plotted in Figure 2 and are compared with the least squares line from Figure 1. The runs made in the light Water-4 are not shown in this figure because they clearly represent nonequilibrium. It is seen that the points from procedures (2) and (3) are in gross agreement with

\begin{tabular}{|c|c|c|c|c|c|c|c|}
\hline $\begin{array}{c}\text { Sample } \\
\text { No. }\end{array}$ & Description* & ${ }^{\circ} \mathrm{C}$ & Water & $\begin{array}{l}\text { Time, } \\
\text { hours }\end{array}$ & $10^{3} \ln \alpha \dagger$ & $\begin{array}{c}\% \\
\text { Exchange }\end{array}$ & $10^{3} \ln \boldsymbol{\alpha}_{\text {。 }}$ \\
\hline 241 & Syn. parag. $+3 M \mathrm{KCl}$ & 600 & 2 & 95 & -0.73 & $82 ?$ & -0.79 \\
\hline 360 & Syn. parag. $+3 M \mathrm{KCl}$ & 600 & 4 & 44 & $(+11.76)$ & 74 & \\
\hline 367 & Syn. parag. + $3 M \mathrm{KCl}$ & 600 & 4 & 160 & $(+5.52)$ & 86 & \\
\hline 356 & Syn. parag. $+2 M \mathrm{KCl}$ & 550 & 7 & 62 & -0.26 & 65 & +0.18 \\
\hline 357 & Syn. parag. $+2 M \mathrm{KCl}$ & 550 & 4 & 62 & $(+13.81)$ & 65 & \\
\hline 233 & Syn. parag. $+3 \mathrm{M} \mathrm{KCl}$ & 500 & 2 & 283 & -0.46 & & \\
\hline 244 & Syn. parag. + $3 \mathrm{M} \mathrm{KCl}$ & 500 & 2 & 312 & +0.15 & $80 ?$ & +0.29 \\
\hline 326 & Syn. musc. $+3 M \mathrm{NaCl}$ & 500 & 2 & 216 & -0.50 & $60 ?$ & -0.10 \\
\hline 292 & Syn. parag. + $3 M \mathrm{KCl}$ & 420 & 2 & 1050 & +0.53 & $65 ?$ & +1.03 \\
\hline 236 & Syn. parag. + $3 M \mathrm{KCl}$ & 400 & 2 & 820 & +0.68 & $60 ?$ & +1.41 \\
\hline 305 & Syn. parag. $+2 M \mathrm{KCl}$ & 350 & 2 & 1120 & +2.21 & 64 & $+3.67 \ddagger$ \\
\hline 306 & Syn. parag. $+2 M \mathrm{KCl}$ & 350 & 4 & 1120 & $+15.25)$ & 64 & \\
\hline
\end{tabular}
the data from procedure (1). In particular, the

TABLE 2. Oxygen Isotope Fractionation Data for Procedure 3

* Syn. = synthetic; musc. = muscovite; parag. = paragonite.

$\dagger$ Values in parentheses are demonstrably non-equilibrium and are not shown in Figure 2. Result No. 233 is anomalous and not comparable to result No. 326; starting materials are not the same preparations and differ by $0.6 \%$ in $\mathrm{O}^{18} / \mathrm{O}^{18}$ ratio.

$\ddagger$ Not used in calculating least-squares expression of Figure 3 (see text).

$\$$ Question mark indicates estimated values. 


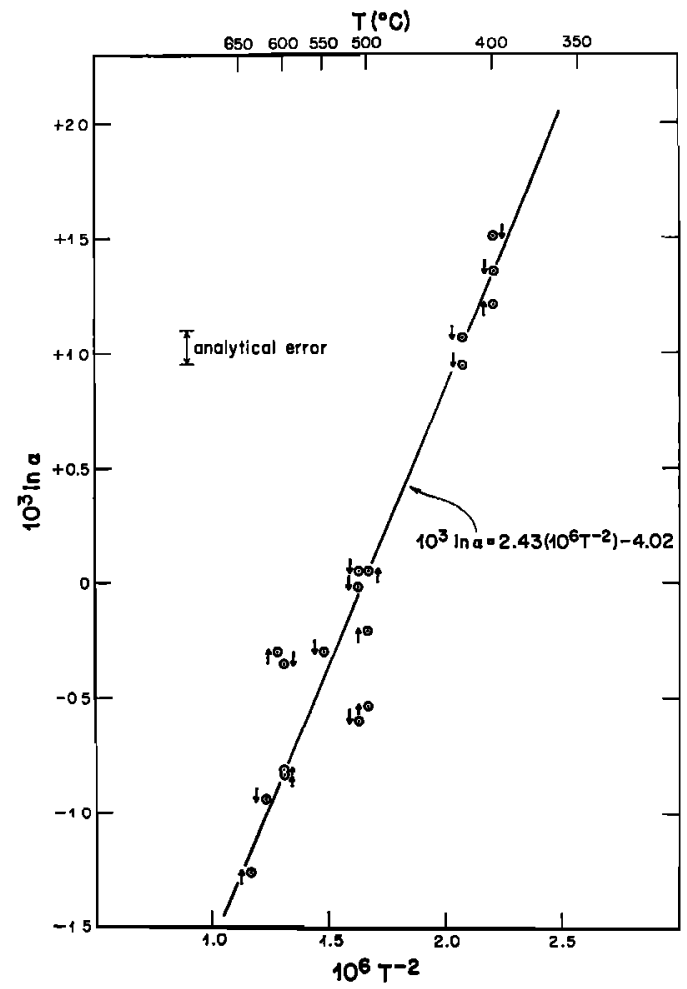

Fig. 1. Plot of $1000 \ln \alpha$ for muscovite-water against $10^{\circ} T^{-2}$, where $T$ is the absolute temperature in ${ }^{\circ} \mathrm{K}$, for data obtained by procedure 1. A least-squares line has been drawn through fourteen of the data points, as discussed in the text. Arrows indicate the direction of approach to equilibrium.

muscovite gel datum is in exact agreement. The direction of the arrows has the same significance as in Figure 1. Note that in general the arrows point in the direction compatible with the interpretation that the exchange reactions were incomplete.

The paragonite-muscovite reactions are closer to true exchange reactions than are the kaolinitemuscovite reactions. The incompletely exchanged runs in the analogous alkali-feldspar system [O'Neil and Taylor, 1967] were shown to yield equilibrium fractionations using the partial exchange extrapolation technique of Northrop and Clayton [1966]. Thus it is instructive to apply this technique to these data. However, inasmuch as oxygen occurs in three distinct structural positions in micas, the various oxygens undoubtedly exchange at different rates with the solution, thus making application of the extrapolation technique more difficult. In fact, Savin and Epstein [1968] have suggested that hydroxyl oxygen in clay minerals exchanges at a considerably faster rate with aqueous solutions than does aluminosilicate oxygen, and also that the hydroxyl oxygen is isotopically different from the aluminosilicate oxygen.

Although it may not be strictly legitimate to apply the partial-exchange technique to the mica-exchange runs for the reasons outlined above, those runs made in Water-2 started so close to equilibrium that the final values of $10^{3}$ $\ln \alpha$ are very insensitive to the per cent of isotopic exchange. The measured values of $10^{3}$ $\ln \alpha$ for procedure (3) and the calculated equilibrium values $10^{3} \ln \alpha_{e}$ are given in Table 2 . In the absence of true companion runs, the degree of exchange had to be estimated in most cases. This was done by noting that all the runs in light water exchanged to the extent of 64 to $86 \%$ and that, as expected, runs of the longest duration and highest temperatures resulted in

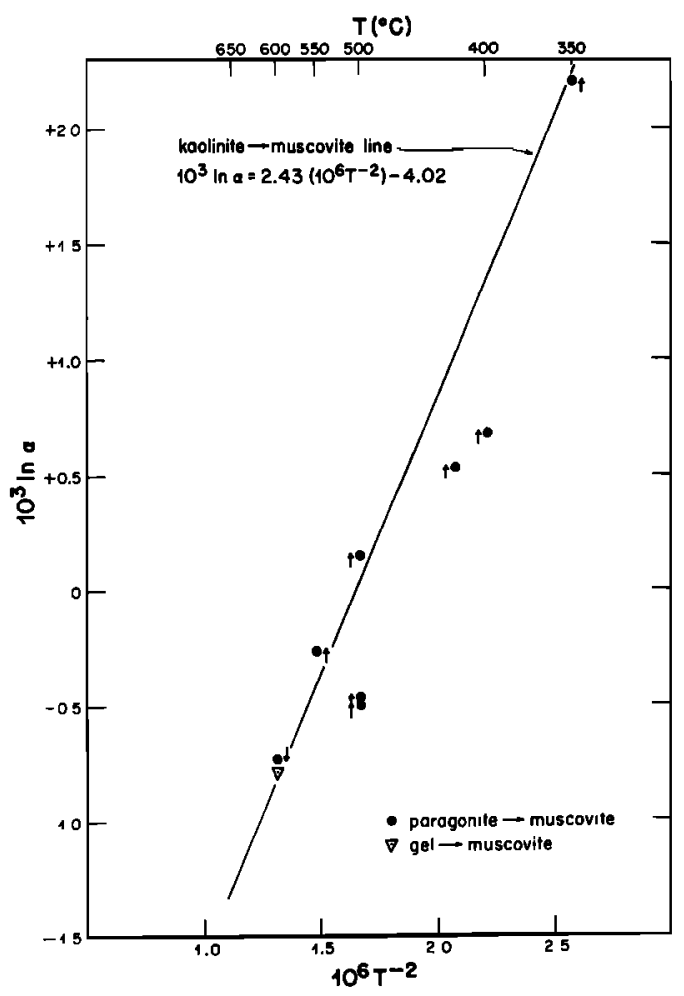

Fig. 2. Comparison of the least-squares line from Figure 1 and the raw data points from procedures 2 and 3 . 
the highest degree of exchange. The estimated values are given in Table 2 , indicated by question marks.

At $350^{\circ} \mathrm{C}$ the extrapolated value of companion runs 305 and 306 is +3.67 , corresponding to an apparent extent of exchange of $64 \%$ in 1120 hours. This extrapolated value is incompatible with the feldspar-water values of +3.93 [O'Neil and Taylor, 1967, Table 1, average of runs 307 and 308] at the same temperature because isotopic analyses of coexisting feldspar and muscovite in naturally occurring assemblages preclude such a small alkali feldsparmuscovite fractionation (see Table 3 ). The $350^{\circ} \mathrm{C}$ extrapolated value is therefore judged to be anomalous and was not used in calculating the final least-squares expression for the musco- vite-water fractionation. It would be fruitless to attempt to identify the source of the problem considering the number of complicated steps involved in obtaining a single data point. It is probable, however, that the extrapolation technique cannot be used for micas except, perhaps, as an approximation when the $\mathrm{O}^{18} / \mathrm{O}^{10}$ extrapolation is very small (thus ruling out the $350^{\circ} \mathrm{C}$ case).

The fourteen 'good' kaolinite-muscovite points, the muscovite-gel point, and the extrapolated values for the paragonite-muscovite runs are plotted in Figure 3. The least-squares expression calculated from these selected data is

$$
10^{3} \ln \alpha=2.38\left(10^{6} T^{-2}\right)-3.89
$$

This expression is the best representation of

TABLE 3. Oxygen Isotope 'Temperatures' of Various Alkali Feldspar-Muscovite Pairs from Igneous and Metamorphic Rocks

\section{$\delta$ Feldspar $^{*} \quad \delta$ Muscovite ${ }^{*} \delta$ Temperature, ${ }^{\circ} \mathrm{C} \dagger$}

Igneous Rocks

1. H-1, 2-mica granite,

Dixville Notch, New Hampshire

2. H-11, 2-mica granite,

Lake Sunapee, New Hampshire

3. T-404, 2-mica granite,

Fitchburg, Massachusetts

4. Elberton Granite

New Comolli Quarry, Georgia

5. Pala pegmatite aplite

Pala, California

6. Trondhjemite (quartz diorite) contact zone of Sawtooth stock, Santa Rosa Mtns., Nevada

$\begin{array}{rrr}8.1\left(\mathrm{An}_{25}\right) & 7.6 & 1400 \pm 500 \\ 10.7(\mathrm{KF}) & 9.6 & 655 \pm 75 \\ 9.4(\mathrm{KF}) & 8.6 & 1000 \pm 200 \\ 8.4(\mathrm{KF}) & 7.3 & 655 \pm 75 \\ 7.6\left(\mathrm{An}_{0}\right) & 6.3 & 530 \pm 50 \\ 12.1\left(\mathrm{An}_{15}\right) & 11.2 & 670 \pm 100 \\ 13.4\left(\mathrm{An}_{15}\right) & 12.7 & 950 \pm 200 \\ 14.2\left(\mathrm{An}_{15}\right) & 13.1 & 520 \pm 75\end{array}$

Metamorphic Rocks

7. EV 13 Chester Dome gneiss

Gassetts, Vermont

8. EV 18, pod in garnet-zone schist

West Marlboro, Vermont

9. LA $10 q$ schist, Mt. Grant, Vermont (chloritoid-kyanite zone)

10. Pelona albite-chlorite-actinolite greenstone schist, San Gabriel Mtns., California

$\begin{array}{rrr}8.2(\mathrm{KF}) & 6.7 & 450 \pm 40 \\ 9.7\left(\mathrm{An}_{10}\right) & 8.2 & 385 \pm 30 \\ 13.9\left(\mathrm{An}_{5}\right) & 12.0 & 315 \pm 20 \\ 12.1\left(\mathrm{An}_{5}\right) & 10.2 & 315 \pm 20\end{array}$

Note: Samples 1 and 2 are from Taylor [1968]; samples 3, 7, and 8 are from Taylor (unpublished data)! sample 4 is from Taylor and Epstein [1962a]; sample 5 is quoted in Epstein and Taylor [1967]; samples 6 are from Shieh and Taylor [1969]; sample 9 is from Taylor et al. [1963]; and sample 10 is from Taylor and Coleman [1968].

* Values of $\delta$ for feldspar and muscovite are reported relative to standard mean ocean water (SMOW). Symbols in parentheses indicate $K$ feldspar (KF) or the anorthite content of the plagioclase $\left(\mathbf{A n}_{0}\right)$ to $\left(\mathbf{A n} \mathbf{n}_{25}\right)$.

$\dagger$ Errors shown for the calculated temperatures are based on the assumption that values of $1000 \ln \alpha$ are accurate to \pm 0.1 . Note that the sensitivity of the feldspar-muscovite geothermometer is very poor at high temperature. 


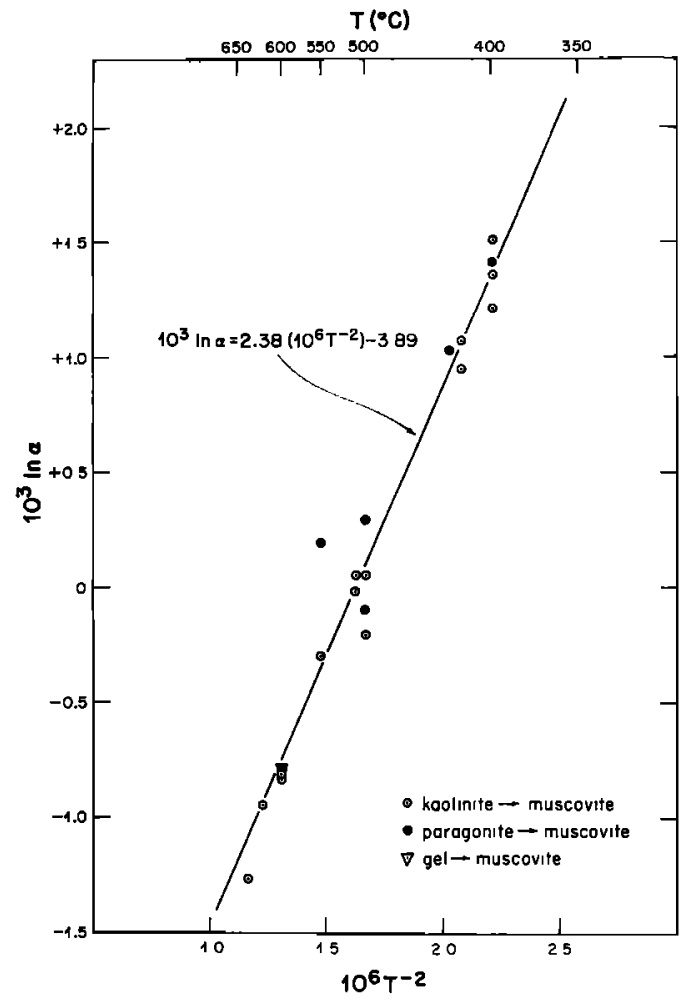

Fig. 3. Plot of $1000 \ln \alpha$ versus $10^{a} T^{-2}$ for the selected muscovite-water fractionations from all three procedures and the least-squares line constructed from these data.

the equilibrium muscovite-water fractionations over the temperature range studied.

Because the reactions utilized in this work involved chemical changes, they are not simple isotope exchange reactions and the equilibrium nature of the fractionations can only be strongly inferred, not proved. It was mentioned in the discussion of the first procedure that the measured fractionations could conceivably be a consequence of kinetic isotope effects. It is the crux of the equilibrium interpretation that the oxygen isotope fractionations obtained with the three procedures are consistent with one another. It would be highly fortuitous if kinetic or other nonequilibrium processes operated in directions so as to produce such systematic isotopic results from three so different procedures.

Additional weight is given the equilibrium interpretation of these data by (1) the linear relation between the per mille fractionations and $T^{-2}$ shown in Figure 1, and (2) the petro- logically very 'reasonable' temperatures that are obtained in a variety of metamorphic rock types with the quartz-muscovite geothermometer [Epstein and Taylor, 1967]. These are, of course, only plausibility arguments and do not constitute absolute proof of equilibrium. There is little reason to expect that the various polymorphs of muscovite would have measurably different isotopic properties, because the essential bond linkages involving the oxygen atoms (Si-O-Si and $\mathrm{Si}-\mathrm{O}-\mathrm{Al}$ ) are not changed. That is, the calibration of the 'metastable' $1 M$ mica produced in these experiments probably applies equally well to $2 M$ micas, the most common form occurring in nature.

The alkali feldspar-muscovite fractionations in igneous and metamorphic rocks are relatively small (0.6 to $1.9 \%$; see Table 3 ). This implies that the feldspar-muscovite isotopic geothermometer is not very temperature sensitive, and analytical errors in the measured $0^{19} / 0^{19}$ ratios result in a large uncertainty in calculated temperatures of formation of natural mineral pairs. Nevertheless, it is useful to calculate crystallization temperatures for those rocks on which isotope measurements have been made on coexisting feldspar and muscovite, particularly because the feldspar- $\mathrm{H}_{2} \mathrm{O}$ calibration of $\mathrm{O}^{\prime} N e i l$ and Taylor [1967] and the muscovite- $\mathrm{H}_{2} \mathrm{O}$ calibration of the present work were both done using cation-exchange techniques in alkali chloride solutions. These calculated 'temperatures' are presented in Table 3 . Note that the 'temperatures' quoted in Table 3 for various igneous and metamorphic rocks are geologically very reasonable, particularly considering the uncertainties involved and the fact that some of these pairs probably did not form in oxygen isotopic equilibrium.

The experiments bearing on the oxygen isotope relationships between muscovite and paragonite are 139 and 142 at $420^{\circ} \mathrm{C}$ and 349 and 351 at $600^{\circ} \mathrm{C}$. These runs show no muscoviteparagonite fractionation, and also the paragonite datum of experiment $61 A$ falls on the same straight line as the good muscovite data. In addition, no observable $0^{18} / 0^{10}$ differences were found between muscovite and paragonite from chloritoid-kyanite zone rocks from Vermont [Taylor et al., 1963]. Hence, although the data are limited, it would appear that the sodium and potassium micas do not measur- 
ably fractionate $\mathrm{O}^{1 s}$ relative to one another at equilibrium. This is consistent with the findings in the alkali feldspar system for which both natural and experimental data indicate identical isotopic properties for the sodium and potassium end members [O'Neil and Taylor, 1967].

\section{Mechanism of the Exchange Reactions}

Based on rate studies and $\mathrm{X}$-ray measurements, Velde [1965] has suggested that portions of the kaolinite crystal structure are inherited intact by the mica in the reaction between kaolinite and $\mathrm{KOH}$ to give muscovite. Inasmuch as kaolinite and muscovite have identical $\mathrm{Al} / \mathrm{Si}$ ratios, the transformation involves only addition of potassium ion and removal of hydrogen ion and water, and the inheritance proposal seemed very reasonable. However, in the reaction of procedure (1) in which potassium is supplied in $\mathrm{KCl}$ solution, the oxygen isotope exchange accompanying the reaction proves that essentially every bond to oxygen in the kaolinite was broken and reformed in constructing the muscovite lattice. That is, all parts of the kaolinite structure are completely broken down in the transformation. In this sense the reaction is identical to the muscovite-paragonite and alkali feldspar exchange reactions in aqueous solution.

One could argue that indeed the initial conversion of kaolinite to muscovite takes place with inheritance of the kaolinite structure, and oxygen isotope exchange subsequently takes place between the mica and water. The rapidity of the isotope exchange (essentially equal in rate to the chemical reaction) argues against this. Also, O'Neil and Taylor [1967] have shown that exchange rates are even slower in solutions containing a common ion (e.g., $\mathrm{K}^{+}$in the solution and in the muscovite) than in pure water.

Further insights into the nature of this reaction are afforded by the 'stripping' experiment 61 and by a comparison of the starting kaolinite and resultant mica by electron microscopy. The photomicrographs in Figure 4 show that the muscovite (in this case produced in 2 hours at $630^{\circ} \mathrm{C}$ ) is well crystallized and of the same average grain size as the kaolinite starting material. This observation suggests a transformation akin to pseudomorphous replacement, and without the oxygen isotope data, this would presumably support Velde's proposal. The knowledge that the oxygen lattice of the kaolinite structure is completely broken down must be reconciled with this observation. It is well known in nature that pseudomorphous replacement can occur with preservation of external forms and delicate internal structures, even though a complete reconstruction of the lattice has obviously occurred (e.g. limonite replacing pyrite, silica replacing wood, etc.).

In experiment 61 , kaolinite was reacted for 180 hours at $510^{\circ} \mathrm{C}$ with a $\mathrm{NaCl}$ solution that was approximately $40 \%$ lower in $\mathrm{O}^{18} / \mathrm{O}^{10}$ ratio than the kaolinite. The solid products were then reacted with $1 / 3$ of the stoichiometric amount of fluorine necessary to liberate all the oxygen from the sample. Inasmuch as the fluorination reaction is believed to take place with the fluorine successively 'stripping' off outer layers of the oxygen-containing solid, this liberated oxygen $(61 A)$ comes from the outer portions of the paragonite grains. The oxygen isotope fractionation between paragonite and water calculated from the analysis of this oxygen is compatible with the equilibrium fractionations measured at other temperatures. The oxygen isotope analysis of the unreacted portions of the grains $(61 B)$ was $2 \%$ heavier than $61 A$; this may indicate an unexchanged remnant core. In other experiments at lower temperatures where reaction was less complete, both kaolinite and mica reflections were observed in the X-ray diffraction patterns.

The stripping experiment and electron microscope observations, in conjunction with the oxygen isotope data, provide information on the detailed nature of the reaction between kaolinite and potassium (or sodium) ion in solution. The starting system is, of course, far removed from chemical equilibrium and the potassium-bearing solution will readily attack a kaolinite grain. Based on analogy with alkali-exchange phenomena in feldspar- $\mathrm{H}_{2} \mathrm{O}$ systems [O'Neil and Taylor, 1967], we conclude that the newlyformed muscovite probably nucleates on the similarly-structured kaolinite in the same grain. Our data show that oxygen isotope equilibrium has been established between this muscovite and the solution, and at sufficiently low temperatures (below the dehydration boundary of kaolinite) the muscovite probably progressively replaces the kaolinite core in the manner of a 


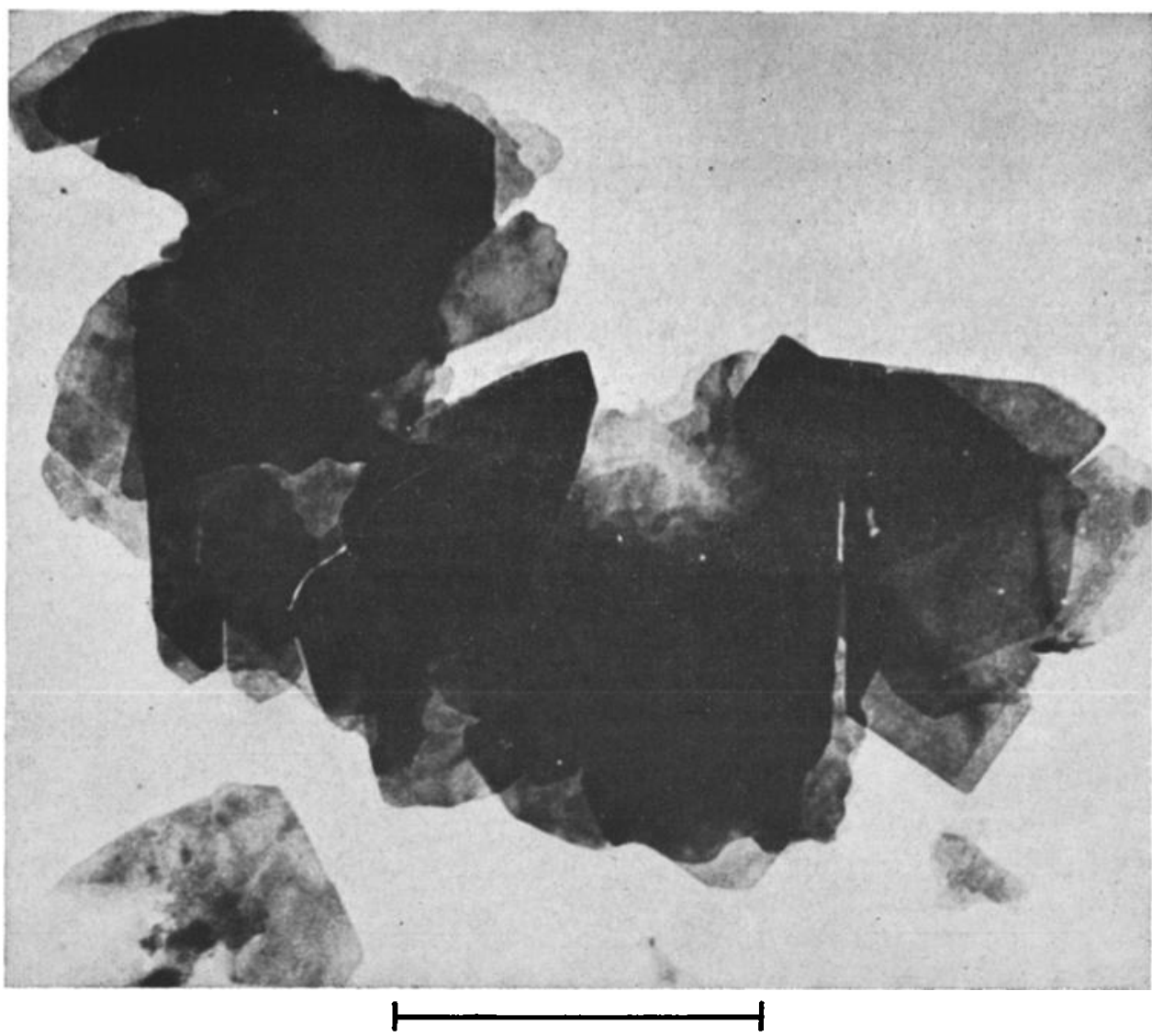

1 Micron

Fig. 4. Photomicrograph of muscovite prepared from kaolinite by reaction with $\mathrm{KCl}$ solution at $630^{\circ} \mathrm{C}$ for 2 hours (above) compared with photomicrograph of the kaolinite starting material (opposite). Allowing for the fact that the mica flakes have adhered together to a certain extent, note that the average grain sizes and general shapes are apparently unaffected by the reaction even though the oxygen has been almost completely exchanged.

reaction front sweeping through the grain. Oxygen isotope equilibrium is maintained between the minute amount of solution present at the reaction boundary and the bulk solution. Chemical communication with the interior of the grain is presumably accomplished through a network of solution pathways generated by the crystal imperfections normally attendant on growth of mineral grains in the laboratory. The observed rapid attainment of oxygen isotope equilibrium at the reaction front is best explained by fine-scale solution redeposition at this boundary, as was postulated for feldspar exchange reactions in aqueous solutions [O'Neil and Taylor, 1967].
Acknowledgments. We wish to thank Professor R. N. Clayton for his helpful criticism of the manuscript, Mr. Paul Yanagasawa for performing most of the fluorine extractions on the solid phases, Dr. John Hudson for help with the electron microscope, and Mrs. Elizabeth Bingham for emission spectrographic analyses.

Financial support was provided by the National Science Foundation, grant GA-513, and by the Alfred P. Sloan Foundation.

\section{REFERENCES}

Baertschi, P., and S. R. Silverman, The determination of relative abundances of the oxygen isotopes in silicate rocks, Geochim. Cosmochim. Acta, 1, 317-328, 1951.

Bigeleisen, J., and M. G. Mayer, Calculation of 


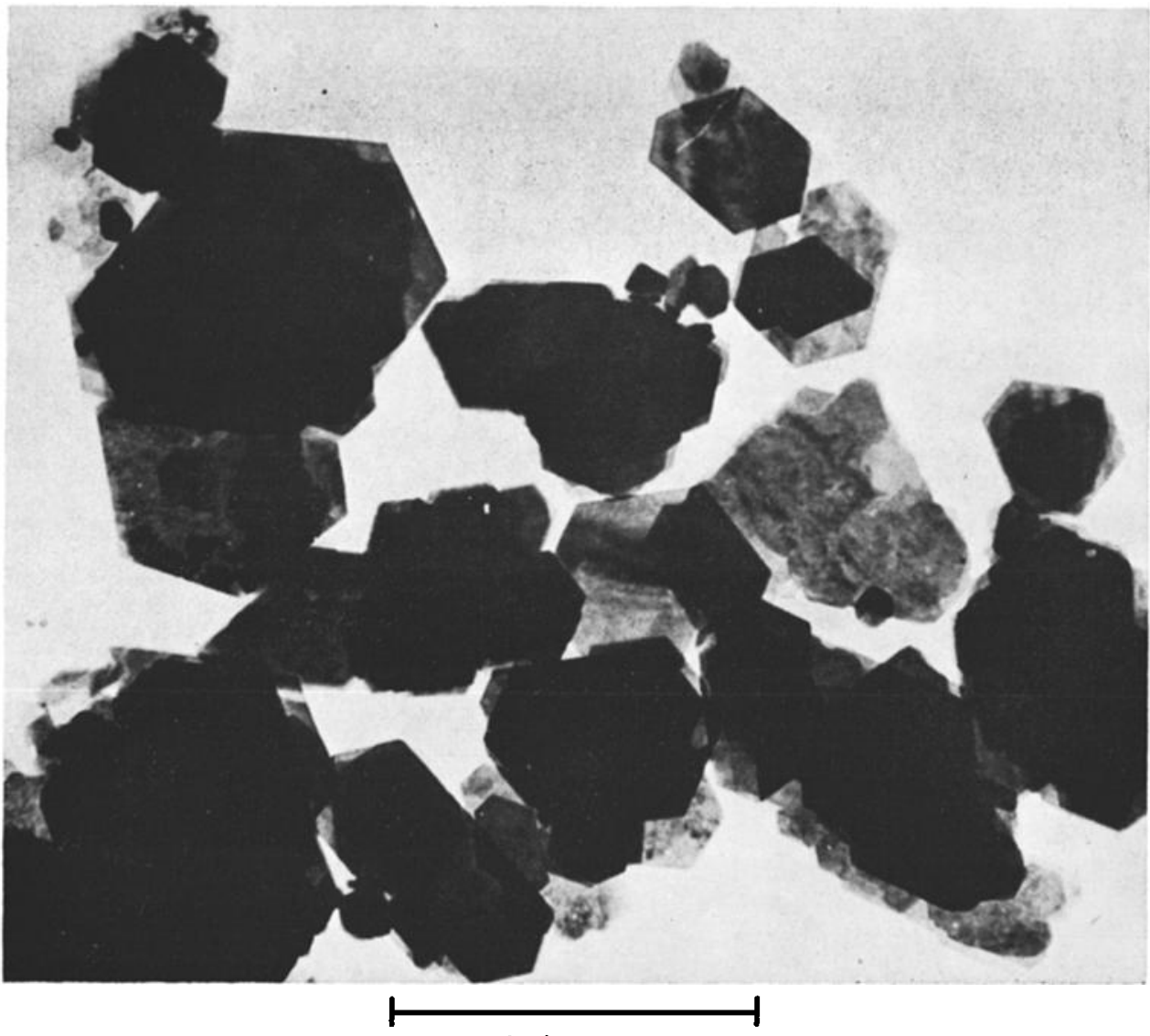

1 Micron

equilibrium constants for isotopic exchange reaction, J. Chem. Phys., 15, 261-267, 1947.

Epstein, S., and H. P. Taylor, Jr., Variation of $\mathrm{O}^{18} / \mathrm{O}^{16}$ in minerals and rocks, in Researches in Geochemistry, vol. 2, edited by P. H. Abelson pp. 29-62, John Wiley and Sons, New York, 1967.

Garlick, G. D., and S. Epstein, Oxygen isotope ratios in coexisting minerals of regionally metamorphosed rocks, Geochim. Cosmochim. Acta, 31, 181-124, 1967.

Northrop, D. A., and R. N. Clayton, Oxygen isotope fractionations in systems containing dolomite, J. Geol., 74, 174-196, 1966.

O'Neil, J. R., and S. Epstein, A method for oxygen isotope analysis of milligram quantities of water and some of its applications, $J$. Geophys. Res., 71, 4955-4961, 1966.

O'Neil, J. R., and H. P. Taylor, Jr., The oxygen isotope and cation exchange chemistry of feldspar, Amer. Mineral., 5\%, 1414-1437, 1967.

Shieh, Y. N., and H. P. Taylor, Jr., Oxygen and hydrogen isotope studies of contact metamorphism in the Santa Rosa Range, Nevada, and other areas, Contrib. Mineral. Petrol., 20, 306356, 1969.

Taylor, H. P., Jr., and S. Epstein, Relationships between $\mathrm{O}^{18} / \mathrm{O}^{16}$ ratios in coexisting minerals of igneous and metamorphic rocks, 1, Principles and experimental results, Bull. Geol. Soc. Amer., 78, 461-480, $1962 a$.

Taylor, H. P., Jr., and S. Epstein, Relation between $\mathrm{O}^{18} / \mathrm{O}^{16}$ ratios in coexisting minerals of igneous and metamorphic rocks, 2, Application to petrologic problems, Bull. Geol. Soc. Amer., 73, 675-693, $1962 b$.

Taylor, H. P., Jr., A. L. Albee, and S. Epstein, $\mathrm{O}^{18} / \mathrm{O}^{18}$ ratios of coexisting minerals in three assemblages of kyanite-zone pelitic schist, $J$. Geol., 71, 513-522, 1963.

Taylor, H. P., Jr., Oxygen isotope studies of hydrothermal mineral deposits, in Geochemistry of Hydrothermal Ore Deposits, edited by H. L. Barnes, pp. 109-142, Holt, Rinehart and Winston, New York, 1967.

Taylor, H. P., Jr., The oxygen isotope geochemistry of igneous rocks, Contrib. Mineral. and Petrol., 19, 1-71, 1968. 
Taylor, H. P., Jr., and R. G. Coleman, $\mathrm{O}^{18} / \mathrm{O}^{18}$ ratios of coexisting minerals in glaucophanebearing metamorphic rocks, Bull. Geol. Soc. Amer., 79, 1727-1756, 1968.

Urey, H. C., Thermodynamic properties of isotopic substances, J. Chem. Soc., 562-581, 1947.

Velde, B., Experimental determination of muscovite polymorph stabilities, Amer. Mineral., 50, 436-449, 1965.
Velde, B., Upper stability of muscovite, Amer. Mineral., 51, 924-929, 1966.

Yoder, H. S., and H. P. Eugster, Synthetic and natural muscovites, Geochim. Cosmochim. Acta, $8,225-280,1955$.

(Received July 31, 1967;

revised June 30, 1969.) 